\title{
"Vizinhança em disputa": A política interna no processo de implantação de uma auditoria fiscal em um condomínio clube na Zona Norte do Rio de Janeiro
}

\section{Caroline Martins de Melo Bottino ${ }^{1}$}

Universidade Federal Fluminense

Lívia Rabelo ${ }^{2}$

Universidade Federal do Rio de Janeiro

Resumo: O cenário político nacional de 2018 teve fortes impactos na sociabilidade da vida urbana brasileira. Neste artigo buscamos analisar o intenso processo de disputas políticas internas que ocorrem em um condomínio clube, na Zona Norte do Rio de Janeiro. Tais disputas reproduzem, em grande medida, as dinâmicas das eleições presidenciais de 2018, polarização que se tornou explícita na movimentação pela sindicatura desse espaço urbano privado. Mediante o protagonismo das mídias digitais nas relações sociais do condomínio, procura-se investigar a mobilização e a articulação dos atores políticos dessa vizinhança. Para tanto, trabalhamos com dados produzidos a partir dos grupos online, onde essas articulações políticas tomam diversas formas, expondo conflitos, fofocas e rupturas que movimentam a vida política desse espaço residencial.

Palavras-chave: condomínio; vizinhança; política; mídias digitais; sociabilidade.

${ }^{1}$ Doutoranda em Antropologia pela Universidade Federal Fluminense, com bolsa Capes, Mestrado em Bens Culturais e Projetos Sociais pela Fundação Getúlio Vargas (RJ). É professora convidada nas pós-graduações em turismo cultural e em educação patrimonial, do Instituto dos Pretos Novos.

2 Doutoranda no Programa de Pós-Graduação em Antropologia Social do Museu Nacional (PPGAS/MN/UFRJ). Mestre em Antropologia Social (PPGAS/MN/UFRJ) e em Economia (CAEN/UFC). Pesquisadora no Núcleo de Antropologia da Política (NUAP). 


\title{
"Neighborhood in dispute": Internal policy in the process of implementing a tax audit in a club condominium in the north of Rio de Janeiro
}

\begin{abstract}
The national political scenario of 2018 had strong impacts on the sociability of the Brazilian urban life. In this paper we seek to analyze an intense process of internal political disputes that occur in a club condominium, in the North Zone of Rio de Janeiro. Such disputes reproduce, to a great extent, the dynamics of the presidential elections of 2018, polarization that became explicit in the movement for the condominium management of this private urban space. In the face of the protagonism of social media in the social and political sphere of the condominium, we investigate the mobilization and the articulation of the political actors in this neighborhood. Therefore, we work with the data produced in these online groups, where these political articulations take different forms, exposing conflicts, ruptures and gossip that drive the political life of this residential space.
\end{abstract}

Keywords: condominium; neighborhood; politics; digital media; sociability.

\section{"Vecinos en disputa": \\ Política interna en un proceso de implementación de una auditoría fiscal en un condominio club en la Zona Norte del Río de Janeiro}

\begin{abstract}
El escenario político nacional de 2018 tuvo fuertes impactos en la sociabilidad de la vida urbana brasileña. En este artículo buscamos analizar el intenso proceso de disputas políticas internas que ocurren en un condominio club, en la zona norte del Río de Janeiro. Tales disputas, en gran medida, reproducen la dinámica de las elecciones presidenciales de 2018, polarización que se hizo explícita en el movimiento por la unión de este espacio urbano privado. A través del papel de los medios digitales en las relaciones sociales del condominio, buscamos investigar la movilización y articulación de los actores políticos de este barrio. Para eso, trabajamos con datos producidos a partir de grupos en línea, donde estas articulaciones políticas toman diferentes formas, exponiendo conflictos, chismes y rupturas que mueven la vida política de este espacio residencial.
\end{abstract}

Palabras-clave: condominio; vecinos; política; medios digitales; sociabilidad, 
$\mathrm{E}$ m 08 de abril de 2018, o ex-presidente Luís Inácio Lula da Silva (Lula), se entregou a polícia federal 3 , no processo desencadeado pela Operação Lava Jato4. Nesse momento, em um condomínio clube, na Zona Norte da cidade do Rio de Janeiro, teve início um movimento de descontentamento com a administração realizada pelo então síndico, José Olavo. Movidos por um sentimento de justiça que pairava no ar, com o objetivo de "combater a corrupção" 5 , moradores se articularam para pleitear uma auditoria fiscal nas contas da atual gestão.

Desde Wyne (1998) e seu estudo sobre o novo estilo de vida das camadas médias, a partir de um condomínio planejado, onde o principal atrativo é um clube privativo, compartilhado apenas pelos residentes, até o que Caldeira (1997; 2000), chamou de enclaves fortificados, os condomínios clube despertam o interesse dos pesquisadores por concentrarem os mais variados tipos de sociabilidade e permitirem análises múltiplas. Por ora, vamos nos remeter a Moura (2003), que chamou a atenção para essas novas formas de habitar como um desejo de retornar à aldeia, para justificar as premissas que vamos adotar, mais adiante, a respeito da dinâmica política interna.

O presente objeto de estudo, o condomínio Quintal Suburbano ${ }^{6}$, conta com 524 unidades habitacionais, divididas em quatro blocos de apartamentos, com 13 pavimentos cada, voltados para uma área de lazer com: duas piscinas, quatro churrasqueiras, salão de festas, salão de jogos, duas quadras, sauna, parque infantil, pista de caminhada etc., é um modelo potencialmente paradigmático desse tipo de habitação. Para além disso, possui, também um bar social, que funciona diariamente vendendo refeições, lanches e bebidas alcóolicas que podem ser consumidas no local, próximo à piscina, na área de lazer, ou entregues nas unidades. Embaixo dos blocos, suspensos por pilastras, encontram-se outras áreas de sociabilidade como: mesas de jogos, espaços para confraternização, banheiros e um parquinho para bebês. Construído no terreno de uma antiga fábrica de vidros, ele compõe um complexo maior, com mais três outros empreendimentos de semelhante porte, que variam em número de blocos e configurações.

3 Para um relato sobre a efervescência no momento da entrega do ex-presidente Lula à polícia federal ver Lagüéns (2018). 4 A Operação Lava Jato, deflagrada pela Justiça Federal em 2014, investigava um grande esquema de lavagem e desvio de dinheiro em âmbito nacional.

5 Em itálico estão as palavras estrangeiras. Entre aspas estão as categorias "nativas" e citações textuais com menos de três linhas.

6 Todos os nomes são fictícios, buscando preservar a identidade dos indivíduos, contudo, Bottino possui a permissão dos condôminos para a realização da pesquisa, uso dos dados, nome do empreendimento e imagens dele, devidamente registrada em ata, lavrada em cartório. 
Figura 1: Planta baixa disponível no material promocional distribuído no stand de vendas construtora em abril de 2010. (Acervo pessoal)

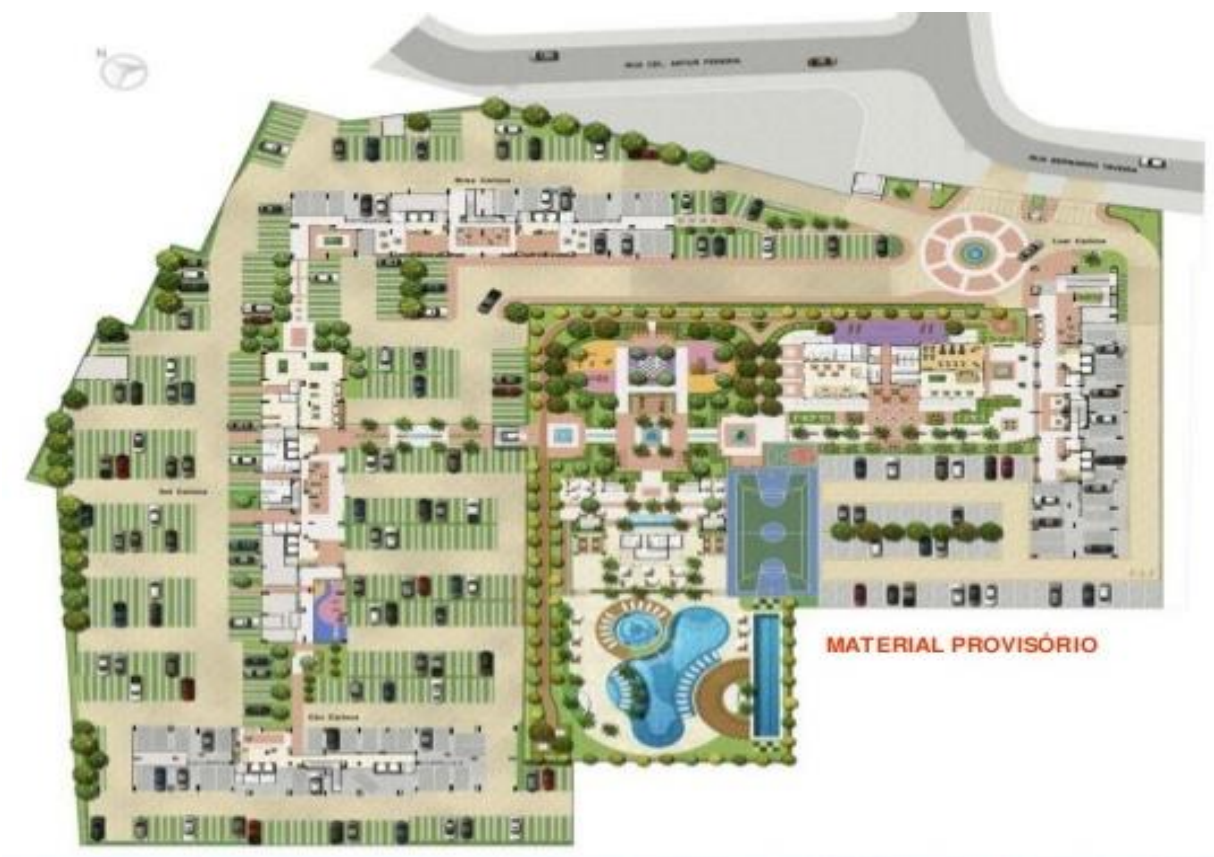

No que tange o perfil dos moradores, de acordo com uma pesquisa quantitativa, aplicada em março de 2020, grande parte deles já residia nessa região antes de se mudarem para o condomínio. Quanto a configuração familiar, 40\% dos apartamentos são habitados por 3 pessoas e $65 \%$ possuem crianças e/ou adolescentes. Com relação a renda média, $58 \%$ declararam receber acima de oito salários-mínimos e a segunda faixa salarial mais expressiva, 15\% dos entrevistados, recebem entre três e cinco salários-mínimos. Quando perguntados sobre a forma de aquisição do apartamento, 54\% responderam que são proprietários, mas ainda estão pagando as parcelas do financiamento bancário, 33\% já quitaram o imóvel e apenas $13 \%$ são inquilinos.

Lançado para vendas em março de 2010 e entregue aos seus compradores em maio de 2014, ele se destaca dentre dos demais dessa categoria no que tange a constituição das relações de vizinhança, que se deu por meio das plataformas digitais de comunicação, através, primeiramente, da plataforma de e-mails do Yahoo Groups, ainda no período de obras e posteriormente seguiu para o Facebook e o WhatsApp. Um condomínio online e uma vizinhança ativa, são o terreno profícuo para o estudo de caso que aqui nos propomos a realizar.

O Quintal Suburbano é o objeto de investigação do projeto de tese de doutoramento de Bottino, também local de sua residência. Esta tem por objetivo compreender esse complexo residencial, em suas particularidades, concentrando-se em questões como as suscitadas por Velho (1989): camadas médias, projeto de vida, ascensão social por meio da habitação, sociabilidade, conflitos etc. Já Rabelo, pesquisa sobre trajetórias de lideranças religiosas, sindicais e político-partidárias em pequenos municípios da Zona da Mata Mineira, discutindo sobre sociabilidade, parentesco biológico e por consideração (vizinhança), dilemas morais nas migrações entre facções no interregno das eleições municipais.

Posto isto, o presente artigo reúne os esforços das autoras e seus respectivos arcabouços teóricos para refletir sobre a dinâmica política entre vizinhos, que se 
desenvolve nesses complexos residenciais de grande porte, considerados "pequenas cidades" dentro das grandes metrópoles. Busca compreender os impactos do contexto político nacional nas mobilizações internas, além de evidenciar como essa busca pelos enclaves fortificados e um possível desejo de retorno a aldeia, constrói novas formas de sociabilidade que não é a urbana, nem a rural, mas a condominial.

\section{"Os estabelecidos e as alianças": a trajetória de formação da vizinhança online}

Em 9 de outubro de 2010, meses após o início das vendas, Klaudia Flores montou o primeiro grupo de futuros vizinhos na plataforma de e-mail do Yahoo!. Esse grupo era um fórum de mensagens, com uma página onde se tinha acesso por meio de uma conta de e-mail nesse provedor. Ele contava com um fluxo de 22 a 100 mensagens por mês, para um total de 108 membros. Os assuntos tratados nele alternavam entre fotografias do terreno e acompanhamento dos estágios da obra, até dúvidas sobre questões burocráticas, como pagamento de impostos referentes ao processo de aquisição e documentações pendentes que estavam atrasando o andamento da construção.

Por meio desse grupo, começaram a ser construídas as relações de vizinhança, resultando em encontros presenciais para confraternização, ainda no período de obras. Um desses encontros, que aconteceu em uma famosa pizzaria do bairro e contou com a participação de aproximadamente 10 famílias, foi fotografado e compartilhado na página do grupo. Em 16 de abril de 2011, foi criado o primeiro grupo na plataforma Facebook, chamado Quintal Suburbano, que chegou a ter 466 membros. Após a entrega das chaves o grupo de e-mails foi perdendo seu protagonismo para a plataforma do Facebook dado o layout mais visual das interações com a possibilidade de compartilhar imagens e vídeos, interagir com textos e mensagens, sem a necessidade de redigir um e-mail. $O$ formato em aplicativo de celular também facilitava o acesso, tornando esse grupo, até 11 de agosto de 2015, o principal canal de comunicação entre os vizinhos (BOYD e ELLISON, 2007).

Tão logo as chaves foram entregues aos compradores, em 2014, as discussões no grupo do Facebook foram se intensificando, devido aos conflitos oriundos da convivência. Durante a assembleia de implantação do condomínio7, já era possível perceber o grupo dos "estabelecidos" (ELIAS e SCOTSON, 2000), que compreende Pietra Malaquias, Klaudia Flores, Sandro Palomino, Flávio Aragão, Dodô Taveira e Flávio Noronha, previamente articulados. Os primeiros administradores do grupo, Klaudia Flores - que também havia sido responsável pelo grupo no Yahoo! - e Dodô Taveira se sentiram desconfortáveis em continuar moderando as postagens e resolveram bloquear assuntos que pudessem gerar polêmicas, como reclamações sobre comportamentos de vizinhos, expondo imagens e vídeos. Isso resultou na criação de um segundo grupo, dessa vez administrado por Sandro Palomino, com o nome Quintal Suburbano (Moradores), que assumiu a centralidade como canal de comunicação.

Em 13 de janeiro de 2016, Maura, dissidente do grupo de Palomino, uma personagem influente nessa dinâmica, que veremos mais adiante, criou outro grupo no Facebook, chamado Quintal Suburbano Clube, contando com 338 membros.

7 Esse evento faz parte do processo de inauguração de um novo condomínio, onde é apresentada a convenção, o regimento interno, a dotação orçamentária e a síndica profissional contratada pela construtora. 
Ambos funcionavam simultaneamente, a princípio todos do grupo de Maura também estavam no grupo de Palomino, porém o inverso não acontecia, já que havia uma rivalidade entre os administradores dos grupos e, consequentemente, entre seus aliados. O primeiro grupo no WhatsApp surgiu em 31 de maio de 2016, com o nome de Associação dos Moradores, tendo por objetivo construir uma espécie de coletivo que estava descontente com a administração do condomínio, para debaterem os assuntos relacionados a finanças e a gestão. O criador do grupo, Alex, se desentendeu com alguns membros, Aragão e Palomino, fazendo com que logo no início ele deixasse o grupo, assim, deixando sua administração nas mãos dos acima citados.

Em 12 de novembro de 2017, Maura criou também o seu próprio grupo de WhatsApp, chamado Por um Quintal Melhor, após se desentender com os administradores do outro grupo. Os grupos passaram a existir simultaneamente, repetindo, muitas das vezes, os mesmos debates. Entretanto, o grupo moderado por Maura tinha o caráter mais político, voltado apenas a questões referentes ao condomínio, com uma moderação rígida, onde ela se guardava o direito de advertir e/ou expulsar os membros por mensagens e condutas que classificasse inapropriada. Já o grupo Associação dos Moradores, depois da mudança de administradores passou a ser um espaço mais genérico, permitindo discussões sobre assuntos do cotidiano, comércio e política em âmbito nacional.

\section{"Do golpe à auditoria": as disputas políticas internas pela administração do condomínio}

Foi na gestão do síndico Flávio Noronha, que Bottino começou a se envolver mais ativamente nas questões do condomínio, incentivada pela sua principal interlocutora, Pietra Malaquias. Uma pessoa muito influente no condomínio, simpática e amigável, costuma receber em sua casa muitos vizinhos, se mostrando sempre disposta a ajudar em qualquer situação. Ela fazia parte do primeiro grupo de e-mails no Yahoo!, através do qual se conheceram. Nesse período, ela formou um grupo de moradores insatisfeitos que contava com a participação de Poliana, Fraga, José Olavo e de Bottino. Eles costumavam fazer reuniões no salão de jogos e na casa da Pietra para discutir as falhas da gestão do síndico Noronha. Algum tempo depois, José Olavo e Fraga acabaram se afastando do grupo à medida que resolveram se candidatar aos cargos de síndico e conselheira, respectivamente.

A seguir, traçamos uma cronologia das gestões do condomínio a fim de compreender melhor esse processo. Em 2014, como referido acima, houve a assembleia de implantação do condomínio, com uma festa, organizada pela construtora. Nesse dia o grupo dos "estabelecidos" se sentaram nas primeiras fileiras. Previamente articulados, indicaram o subsíndico e os conselheiros, gerando uma grande confusão com gritaria, aplausos e cornetas na hora da votação. Desse modo, a primeira gestão ficou dividida entre uma síndica profissional, contratada pela construtora, e um subsíndico, Flávio Noronha, eleito pelos moradores, com "Jú do André", Dodô Taveira e Bretas no conselho fiscal ${ }^{8}$.

No final de 2014, através do grupo, Quintal Suburbano, no Facebook, Sandro Palomino acusou, juntamente com Dodô, a síndica profissional de estar roubando nos contratos de prestação de serviço. Usavam também como premissa o fato dela não residir no condomínio, o que tornava a comunicação muito difícil, pois estava

${ }^{8}$ A estrutura de administração de um condomínio consiste em um síndico, que atua como gestor principal, um subsíndico, que tem o papel de substituir o síndico na sua ausência, um conselho fiscal, formado por moradores. Condomínios clube, contam também com uma empresa de administração para cuidar da parte financeira e o síndico pode ser morador, um profissional contratado ou uma empresa de sindicância. 
disponível apenas em horário comercial. Com isso, conseguiram o apoio dos moradores e, pressionada, a síndica renunciou, durante o carnaval de 2015, levando Flávio Noronha, como subsíndico, a assumir o cargo de forma interina.

O regimento interno do condomínio previa a convocação de uma nova eleição, mas ela não aconteceu, deixando desprovido o cargo de subsíndico. Segundo Pietra Malaquias, tudo não passou de um golpe: "o combinado entre Noronha e Palomino era que uma eleição fosse convocada para que Sandro Palomino assumisse a sindicância, mas Noronha quis, de última hora, se manter no cargo, criando um grande mal-estar entre os dois". Para além das questões condominiais, conflitos pessoais influenciaram no combinado e levaram ao rompimento da amizade entre eles. Por isso, meses depois, deu-se a origem ao segundo "movimento de oposição", liderado por Sandro Palomino.

Noronha não conseguiu lidar com a pressão que Palomino construiu por meio dos grupos online, expondo as falhas da gestão, incitando os moradores contra ele e acabou renunciando ao cargo, no final de 2015. Sem síndico e subsíndico eleitos, José Olavo se prontificou a assumir a gestão por três meses, de forma voluntária, até que surgissem candidatos ao cargo e fosse convocada uma nova assembleia. Findo o prazo dos três meses, Olavo resolveu se candidatar e acabou sendo eleito, Rainer Melo foi escolhido como subsíndico e para o conselho fiscal foram eleitos Fraga, Cavalin e Aragão.

Após a realização da "Festa Julina"9, no segundo semestre de 2017, as reclamações quanto as manutenções das áreas comuns aumentaram e um grupo de moradores passou a cobrar o retorno da sindicância profissional. Os apoiadores de José Olavo, então síndico, dominavam o grupo de WhatsApp Associação dos Moradores, administrado, até então, por Sandro Palomino e Flávio Aragão. Já os oposicionistas, encontravam maior aderência no grupo Por um Condomínio Melhor, criado por Maura e seu pai, Seu André.

Quando o assunto auditoria fiscal surgiu no grupo da Maura, sugerido por Poliana, as discussões ficaram mais acaloradas, levando os moradores a cogitarem exigir isso na próxima assembleia. Em dezembro de 2017, José Olavo se afastou do cargo, por motivos de saúde. No mesmo mês, a gerente que o assessorava sofreu um acidente de carro e faleceu. Esses episódios provocaram ainda mais debates acerca da administração do condomínio, que nesse momento se encontrava sem gestor. $\mathrm{O}$ afastamento de José Olavo foi oficializado somente no final de janeiro de 2018, quando o subsíndico, Rainer Melo, assumiu.

Dentre as muitas insatisfações dos moradores estavam a disparidade nas cobranças das contas de água ${ }^{10}$, bem como o valor da dívida de inadimplência, que já passava de R\$ 600 mil. Estimulados por Maura, que postava em seus grupos os defeitos da administração atual, começou a mobilização para convocação de uma assembleia extraordinária com o intuito de contratar uma empresa de auditoria fiscal. Uma resistência muito grande surgiu por parte do conselho fiscal, que tinha como membro Flávio Aragão, um dos administradores do grupo de WhatsApp Associação dos Moradores. Se desvios e irregularidades nas contas fossem detectados, o conselho fiscal, cuja função é justamente conferir a contabilidade do condomínio, seria igualmente responsabilizado.

\footnotetext{
9 A festa julina casou muito desconforto, foi autorizada por José Olavo, como confraternização interna, mas acabou recebendo pessoas de fora do condomínio mediante ao pagamento de "ingresso", o que acabou alimentando ainda mais a insatisfação com a gestão do síndico.

${ }_{10} \mathrm{O}$ condomínio disponibiliza hidrômetros individuais que permitem a marcação exata do consumo de cada unidade, porém, a cia de abastecimento, CEDAE, não faz essa leitura individual, sendo necessário a contratação de uma empresa para a medição e cálculo do rateio.
} 
Essas duas facções se enfrentaram através de grupos de WhatsApp separados. Mesmo não contando com a participação de todos os residentes no condomínio, o fluxo diário de interações nessas plataformas chegava à marca de mil mensagens não lidas em um período de seis horas. Diante dos ânimos inflamados, o conselho fiscal, na tentativa de apaziguar a situação, convocou uma reunião informal com os condôminos, para se justificar. As explicações não convenceram a todos e os membros do grupo Por um Condomínio Melhor começaram a se articular para convocar uma assembleia.

Começaram de forma cordial, pedindo ao síndico interino Rainer, por meio de uma carta, protocolada por Maura, que seguiu cobrando presencialmente quase que diariamente e informando sobre o processo nos grupos online que administra, mas sem sucesso. Findadas as inúmeras tentativas de acordo, ela então decidiu organizar um abaixo assinado para convocar uma assembleia. Assim, em março, Maura, Tânia e Eliane se revezaram para colherem assinaturas, batendo de porta em porta e se disponibilizando a receber em sua casa quem quisesse assinar.

Enquanto isso, no outro grupo de WhatsApp, Aragão e Tatiana Fraga, membros do conselho fiscal, afirmavam que não havia irregularidade alguma na gestão de Olavo e que não tinha motivo para contratar uma auditoria. Aragão, Palomino e Fraga, vale ressaltar, são parte dos "estabelecidos", que estão envolvidos com a administração do condomínio e participam ativamente dos grupos online desde o período de obras. São protagonistas não só nos grupos como nas assembleias, candidatam-se e/ou apoiam nomes para cargos na administração.

Maura entregou o abaixo-assinado ao síndico Rainer e à $\mathrm{PAB}$, empresa responsável pela administração do condomínio, para que fosse convocada a assembleia. Ao mesmo tempo, Tânia e Maura pediram orçamentos de empresas de auditoria contábil para apresentar aos moradores no dia da reunião. Os moradores que faziam parte do grupo de WhatsApp administrado por Maura, o Por um Condomínio Melhor, escolheram juntos os itens a serem revisados pela auditoria e os orçamentos recebidos foram sendo postados por ela. Devido a um desentendimento com Maura, Tânia acabou saindo do grupo e continuou sozinha seu próprio trabalho de tomada de preços. As duas, portanto, passaram a disputar a indicação da empresa auditora.

\section{"Fora PT! Fora PT!": por uma assembleia de combate à corrupção}

No dia da assembleia, 30 de abril de 2018, o clima era de tensão pela expectativa de um possível embargo por parte de Rainer e Aragão. Nos grupos, o debate girava em torno dos orçamentos das empresas de auditoria candidatas ao serviço. Próximo do início da reunião, Eliane, mais conhecida como "Lis do Zé11", foi chamada a comparecer na sala da administração. Desconfiando dessa atitude, comunicou a Tânia, que por sua vez avisou a Poliana e Pietra. Sendo ela a nossa principal interlocutora, Pietra tratou de chamar Bottino para acompanhar esse encontro. Antes de entrar na sala, Lis explicou que o síndico a chamou para conversar, por ela ser uma das representantes do movimento e que achou prudente chamar outras pessoas para acompanhar a conversa. Vale ressaltar que apesar de Maura ter encabeçado o movimento, ela e Aragão possuem um desentendimento e por isso, ele teria escolhido chamar a Lis do Zé ao invés da Maura.

${ }^{11}$ Observou-se, durante a pesquisa, que muitos casais possuem o hábito de utilizarem como nome, em suas redes sociais, essa referência ao companheiro, como: Jú do André, Lis do Zé, Breno da Flávia e etc. 
Elas seguiram para a administração onde as aguardavam o síndico, Rainer, e o presidente do conselho, Aragão. Ao chegar, Lis perguntou o motivo do convite e Aragão respondeu enaltecendo o trabalho do conselho fiscal, dizendo que não via necessidade na contratação de uma empresa de auditoria. Enfurecida, Pietra começou a gritar, citando as principais queixas que levaram ao pedido de auditoria, como o não-depósito do fundo de reserva, mesmo as contribuições sendo descontadas mensalmente dos condôminos, a disparidade na cobrança da água individual e o valor da dívida da inadimplência. Ela o culpava por não alertar os moradores e ser conivente com os erros da empresa administradora e do síndico. Já Poliana, que dispunha de uma pasta com muitos documentos impressos, levantou-se e ameaçou ir para a delegacia instaurar um processo criminal contra o síndico.

Rainer então informou que o abaixo-assinado era inválido pois faltavam 30 assinaturas. Quando as conferiu, percebeu depois que algumas não eram de proprietários ${ }^{12} \mathrm{e}$, portanto, não valiam. Disse também que havia cancelado a vinda do escrivão da empresa $\mathrm{PAB}$, administradora do condomínio, responsável pela organização e registro da ata das assembleias. Revoltada, Pietra arrancou o papel da mão dele e saiu da sala dizendo que iria buscar o restante das assinaturas. No meio do caminho, encontrou Maura e seu pai, André, que perguntou o que estava acontecendo, já que não haviam sido informados sobre a reunião. Depois de descrever o ocorrido, Seu José pediu calma pois a assembleia já havia sido convocada oficialmente e se o síndico não validou as assinaturas antes da convocação, o erro era dele. Quanto à ausência do escrivão da $\mathrm{PAB}$, bastava gravar a reunião e usar a transcrição como ata.

Chegando para a Assembleia, às 19h, muitos moradores já se encontravam no local do evento, abaixo da área de lazer, no estacionamento coberto, aguardando. Representantes das empresas de auditoria também já haviam chegado. Pietra notou que nem o síndico e nem os funcionários da administração estavam presentes e resolveu ir até a sala da administração. Ao chegar, encontrou os advogados da empresa Marzone, que prestavam serviços ao condomínio, junto com Aragão e Cavalin, conversando em uma sala reservada. Então pediu à gerente que imprimisse a lista de moradores e fornecesse os cartões ${ }^{13}$ para dar início à assembleia, os advogados vieram na sua direção, afirmando que a assembleia era improcedente e que estavam ali para resolver o mal-entendido.

Saíram todos juntos da sala e quando chegaram ao local da reunião, os advogados ficaram surpresos: havia mais de 150 moradores, número expressivo para uma assembleia de condomínio, e acabaram desistindo de falar qualquer coisa, se limitando a dizer que estavam lá apenas para acompanhar a assembleia e dar suporte aos moradores. A clara tentativa de impedir a assembleia por parte do síndico, com apoio do conselho fiscal gerou um imenso desconforto entre os condôminos, vindos em massa, mesmo diante de um dia chuvoso. Para presidência da mesa foi eleito o Seu André, pai da Maura, e como secretária, para redigir a ata, a Senhora Poliana. Os representantes das empresas apresentaram seus orçamentos e as vantagens de cada proposta, depois se retiraram para que fosse realizada a escolha.

O momento da votação foi bastante tumultuado. Maura queria muito a escolha de uma empresa que havia indicado e até tentou desmerecer as outras, mas

12 Para a convocação de uma assembleia, de acordo com o regimento interno, é necessário que seja exigida por $1 / 3$ dos condôminos, sendo estes proprietários e/ou procuradores dos mesmos e com suas cotas condominiais quitadas. Inadimplentes e inquilinos não possuem poder de voto.

13 Os cartões são usados para contabilizar os votos, são feitos de papelão com duas cores, de um lado azul e outro amarelo. Quando solicitada a votação o morador levanta seu cartão e os votos são contabilizados. 
após as apresentações, os moradores estavam mais inclinados a contratar uma das empresas cotadas por Tânia. Quando a votação começou, as pessoas levantaram seus cartões, favoráveis à ODB Auditores, que foi contratada. Nesse momento, os participantes se levantaram e aplaudiram em comemoração; em seguida começou um coro gritando: "Fora PT! Fora PT! Fora PT!". A participação de um número expressivo dos moradores, com 133 condôminos votantes, e seu entusiasmo pelo resultado, deram à essa reunião de condomínio um ar de final de uma partida de futebol.

O próximo passo era eleger uma comissão de moradores para acompanhar o processo da auditoria, já que a administração, o síndico e o conselho fiscal não podiam supervisionar o serviço, por estarem envolvidos no que seria auditado. Maura foi a primeira a se candidatar seguida por Lis do Zé, que ajudou a colher as assinaturas, e Tânia, que fez a tomada de preços e trouxe a empresa eleita. Os condôminos aprovaram todas as pessoas que se candidataram e a reunião acabou próximo da $01 \mathrm{~h}$ da manhã. Ao término muitos moradores ainda ficaram conversando pelas áreas comuns. Através dos grupos online, Facebook e WhatsApp, moradores informavam, em tempo real, o andamento da assembleia e lá os debates continuaram por semanas.

\section{"De fora para dentro, atravessando os muros": reflexões sobre dinâmica faccional e contexto político nacional em um condomínio/cidade}

As disputas eleitorais para a administração do condomínio ocorrem a cada dois anos. $\mathrm{O}$ ano de 2018 apresenta a sincronia de ser, ao mesmo tempo, o ano de eleições para presidente da república e para um novo síndico no condomínio. Se em nível nacional se iniciava o "tempo da política" (PALMEIRA, 2010), em nível condominial esse processo também estava próximo. No âmbito nacional, o clima era de tensão, acusações e contra-acusações, formando um contexto altamente inflamando por discursos que associavam diretamente o Partido dos Trabalhadores (PT) à corrupção. Diante da transformação de escândalos em shows midiáticos tornando seus temas em assuntos cotidianos (CIOCCARI, 2015), percebemos que esse ambiente penetrou os muros do condomínio estudado.

A prisão do ex-presidente Lula, em abril de 2018, abriu brechas para campanhas eleitorais não oficiais. Tais campanhas não se configuraram especificamente a favor de um candidato ou partido, mas contra alguns políticos, com ênfase para os petistas. Se esse cenário se apresentou como perseguição política para alguns, também se apresentou como a "limpeza da casa" para outros. É esse o ponto que enfatizamos aqui: numa região antipetista, como a estudada, o sentimento de busca por justiça e fim da corrupção afetou consideravelmente as relações na vida cotidiana.

Uma questão importante, suscitada pela Assembleia, foi a inversão da oposição versus situação. Desde 2014 quando houve a transição de "síndico profissional" para morador, Flávio Noronha, a figura do "síndico morador" se estabeleceu como situação e foi sucedido por Olavo e Rainer. Apenas após a Assembleia, aqui descrita, com o retorno do modelo de sindicância profissional, e a contratação da empresa Predileto, a oposição se torna situação e assume a administração do Quintal Suburbano.

Tomando como base os trabalhos de Palmeira (2010) e Palmeira e Heredia (2010) sobre política e facções, e o trabalho de Heredia (2010) sobre conflitos 
internos a uma mesma facção - e cientes da complexidade e do desafio de transportar uma teoria do campesinato para um universo urbano -, nos propomos a refletir sobre as dinâmicas que se assemelham no caso do condomínio. Assim, podemos afirmar que as mobilizações, realizadas principalmente nos grupos online, para o abaixo assinado, são como campanhas eleitorais. A Assembleia pode ser considerada como o evento que marcou oficialmente o "tempo da política", em que o conflito estava autorizado e onde as divergências entre as facções se intensificaram.

Nesse momento a divisão do condomínio em duas facções ficou mais evidente. Os que defendiam a sindicatura de moradores, pela relação próxima com a figura do gestor e sua afetividade com o espaço, por ser também um residente e os que preferiam um síndico profissional, que mantivesse um distanciamento afetivo, para uma gestão idônea e sem favorecimentos a nenhum indivíduo e/ou grupo específico. Sendo, portanto, os que defendem a figura do "síndico morador" orientados por princípios e relações pessoais, enquanto os que defendem a figura do "síndico profissional", reivindicam uma relação impessoal.

Algumas características observadas por Palmeira (2010), como a não fixidez de facções opostas e o papel predominante dos compromissos, tensões, conflitos e aproximações no rearticular das adesões entre uma eleição e outra, nos parece produtiva no contexto desse condomínio.

\footnotetext{
pessoas [que] se relacionam no dia a dia, através de múltiplos fluxos de troca, que vão vinculando umas às outras, confirmando ou não relações preexistentes, cuja interrupção é capaz de gerar conflitos ou redefinir clivagens dentro de uma comunidade. (PALMEIRA, 2010: 19, grifos nossos)
}

Assim, uma tensão dentro de umas das facções, ambiente em que o peso das relações pessoais é de fundamental importância, conflitos pessoais, familiares, de trocas de favores etc., podem provocar dissidências internas. Nessa lógica, é possível que um morador migre de uma facção para outra, já que as relações pessoais estabelecidas de forma presencial e/ou online podem dinamizar a adesão às facções.

Como fruto de um conflito pessoal, Maura se desentende com os administradores do grupo de WhatsApp Associação de Moradores e cria o seu próprio grupo chamado Por um Quintal Melhor. Nesse novo grupo, a articulação de Maura a favor de "síndico profissional" ganha força pela maneira efusiva com que incita os moradores a buscar por melhorias. De forma semelhante, temos também o caso de Fraga, que começou alinhada à Pietra, em oposição à gestão de "síndico morador" e, por questões e interesses pessoais, acabou aderindo e fazendo parte da administração, como conselheira, defendendo a sindicatura de Olavo. Vemos aqui um caso de mudança de facção em que o morador, que até então demonstrava adesão à oposição, se alinha ao grupo da situação e passa a fazer parte da administração.

Os conflitos e interesses pessoais perpassam toda a trama da gestão do condomínio. A amizade de Palomino e Noronha era de grande intimidade, faziam viagem em família etc. Palomino acusa a síndica profissional, no fim de 2014, de roubo nos contratos de prestação serviço, se apresentando assim como alguém que estaria contra gestões corruptas. Noronha assume a administração estabelecendo um combinado de lealdade com Palomino. Entretanto, após uma ruptura pessoal com Noronha, sentindo-se traído (BOIVIN, ROSATO e BALBI, 1998), Palomino articula uma oposição em seu grupo online Associação de moradores forçando a renúncia de Noronha. 
Com isso José Olavo, que era contra o modelo de sindicância "síndico morador" se oferece para assumir por três meses até que surgissem candidatos e fosse convocada uma assembleia. Olavo vence as novas eleições, tendo Rainer como seu subsíndico. É nesse momento que Fraga, também contra esse modelo de sindicância, é eleita para o conselho fiscal. Note que, nesse momento, dois antigos opositores do modelo "síndico morador" fazem parte da administração, mesmo sendo moradores. Entretanto, os "imponderáveis da vida real" (MALINOWSKI, 2018) tomaram conta do condomínio com o afastamento por adoecimento de José Olavo e o falecimento de sua gerente em um acidente. Instaurava-se um ambiente cada vez mais duvidoso do futuro da administração. É nesse contexto que Maura convoca uma assembleia de auditoria fiscal, para investigar as contas de que Fraga é uma das responsáveis.

Vemos como a dinâmica entre o que chamamos de facção é fluida, regada pelas relações pessoais estabelecidas no dia a dia da vizinhança. Embora todos justifiquem estar buscando o melhor para o condomínio e o "fim da corrupção", temos vários grupos se organizando e reorganizando em função não apenas ideológica, mas, principalmente pautados por relações pessoais, seja pelo conflito ou pela proximidade.

Como Miller (2016) demonstrou, as mídias sociais são, hoje, parte do cotidiano dos indivíduos, não cabendo mais a separação entre mundos, assim como se tornou comum, fazer uma chamada telefônica, estamos constantemente alternando as plataformas, dando a cada uma delas um uso específico, para cada momento de acordo com as nossas necessidades. Logo, a vizinhança online se fortalece dentro desse cenário e os grupos no Facebook e WhatsApp tornam-se vitais para a sociabilidade interna, além de ser um ótimo espaço para acompanhar as articulações políticas, onde elas acontecem em sua forma mais latente.

Observamos que essa interação online possibilitou e potencializou a produção de coletivos articulados de forma mais/menos rígida com questões da administração condominial. Seguindo esse raciocínio, argumentamos que, no que tange às relações de vizinhança, dentro do condomínio, os ambientes de sociabilidade físicos que demarcariam espacialmente a adesão às facções - como os bares, as igrejas, campos de futebol etc. - se dão principalmente de maneira online. Esses grupos são os espaços de mobilização e articulação política centrais do condomínio. Embora haja áreas comuns de lazer e serviços, a dinâmica da circulação de informações, acusações e contra-acusações nos grupos se mostra mais eficaz online do que nos espaços físicos. Talvez por ser uma "cidade pequena" inserida numa grande cidade, a cultura das redes sociais tem força notável, ou também pela facilidade de acessar as informações a todo o tempo, sem precisar sequer estar dentro do condomínio para tal (BOYD e ELLISON, 2007).

Refletindo sobre algumas características importantes no processo político em regiões rurais e/ou pequenos municípios que também estão fortemente presentes no condomínio, a política de reputação (BAILEY, 1971) também é importante nessa "pequena cidade" e para o controle da ordem. Vemos também os mecanismos de "vigiar e narrar" (COMERFORD, 2003; 2014). A vigilância pelas varandas e áreas comuns tem papel especial no controle da ação social. Já a narração toma maiores proporções, via Facebook e WhatsApp, aprofundando as discussões sobre os fatos ocorridos nas áreas comuns.

A reputação e prestígio das lideranças são fundamentais para angariar adeptos. A postura de liderança de Maura, sua seriedade e disposição para realizar as demandas lhes renderam certo prestígio entre os moradores. Ela se mudou para o condomínio após a sua inauguração, no final da gestão de Noronha, não fazendo 
parte dos estabelecidos. Desde então começou a se posicionar ativamente na gestão de Olavo, criando seus próprios grupos de WhatsApp. Ao estimular a indignação e se mostrar proativa, fez com que muitos condôminos aderissem à facção que encabeçava. É uma liderança que se destaca por falar bem e entender de legislação (COMERFORD, 2003) condominial. Frequentemente cita parágrafos do regimento interno e matérias do Sindicato da Habitação do Estado do Rio de Janeiro (Secovi Rio), reunindo qualidades desejáveis pelos moradores para uma representação frente à administração do condomínio.

Já o responsável pelo grupo de WhatsApp Associação de Moradores, Palomino, faz parte dos estabelecidos e estava na primeira fileira na primeira assembleia de implantação. Era um grupo muito unido e coeso. Palomino demonstrava afeição pelo protagonismo na vida do condomínio. Ganhou ainda mais destaque quando seu grupo do Facebook se tornou oficial, fazendo dele a sua ferramenta de palanque.

Ao dizer que os moradores estão divididos entre duas facções não queremos dizer que essas facções são homogêneas. Pelo contrário, há sim muitas disputas no interior de uma mesma facção (HEREDIA, 2010). Entretanto, diferentemente do que acontece entre as facções, dentro de uma mesma facção as disputas são veladas e se dão em termos do poder impessoal dos rumores. Nesse sentido, através das fofocas e dos rumores as reputações vão sendo construídas e desconstruídas, afetando a vida pessoal e política das lideranças.

As fofocas, boatos, rumores já foram amplamente explorados pela literatura (PALMEIRA, 2010; HEREDIA, 2010; COMERFORD, 2003; FONSECA, 2004), mostrando a potencialidade e centralidade dessa "forma cotidiana de comunicação e controle social difuso e eficaz" (PALMEIRA, 2010: 171). Já Heredia (2010), trata da fofoca como a narrativa possível dentro de uma mesma facção para que não haja conflitos públicos, afetando diretamente a honra do alvo da fofoca.

É seguindo essa linha de argumentação que percebemos a importância do rumor e da fofoca sobre a vida pessoal e a reputação de moradores envolvidos na administração do condomínio nas conversas online. A vida pessoal dos moradores enredados na disputa pelo "acumular" adeptos, é pública, e acontecimentos pessoais e familiares afetaram diretamente a reputação desses condôminos, levando a rupturas pessoais, como vimos anteriormente, e em casos mais extremos, até a saída do condomínio.

O uso da noção de facções, que acionamos aqui, se apega menos à demarcação espacial e mais à flexibilidade dos moradores entre os coletivos. A mudança de facção dos moradores se dá menos por ideologia que por rupturas pessoais. As divergências que geram as "trocas de lado", são, em sua maioria, de ordem pessoal, oriundas de brigas entre os indivíduos, com pouca ou quase nenhuma relação com a organização política do condomínio.

\section{Considerações finais}

O evento aqui analisado pode ser considerado como um ponto de inflexão a partir do qual podemos perceber como o cenário político externo incide sobre os indivíduos ao ponto de reproduzirem, em um ambiente de menor escala, os anseios em estabelecer um processo de renovação da política interna. Ele acontece em um momento político nacional muito significativo, ano de eleições para pre- 
sidência da república, a prisão do ex-presidente Lula e a ascensão do Bolsonarismo ${ }^{14}$. Sendo a região onde o condomínio se localiza, Zona Norte da cidade do Rio de Janeiro, um local de forte presença do antipetismo, como ficou evidente no final da descrição do episódio da Assembleia. Observou-se uma estreita relação entre o contexto macro, dos fatos em curso na política nacional, com as movimentações políticas internas que se iniciaram, no evento em questão. Imbuídos de uma espécie de senso de justiça, estimulados por uma "indignação coletiva" (PINHEIRO-MACHADO e FREIXO, 2019), diante da mobilização nacional para o fim da corrupção, iniciou-se uma articulação para investigar a gestão do condomínio, com o objetivo maior de mudar não só o síndico, mas também o tipo de sindicatura. Os moradores, insatisfeitos com a atual gestão e com a política em âmbito nacional se mobilizaram por mudanças dentro daquilo que possuem mais gerência, a sua própria residência.

É emblemático que em meio ao conturbado desenrolar do processo eleitoral brasileiro, em 2018, a vizinhança em um condomínio clube se movimente em direção a buscar investigações sobre irregularidades administrativas, se mobilize coletivamente em prol de uma mudança no modelo de gestão e queira encontrar culpados para serem punidos, nesse caso o síndico e o conselho fiscal. Aqui então se apresenta, às vésperas não só da votação para presidente da república, mas também da assembleia geral ordinária, que indicaria o novo gestor e modelo de gestão do condomínio, um evento que marca uma mudança de paradigma e também expressa as diferentes escalas da política incidindo sobre o cotidiano dos indivíduos.

Em outro momento, os gritos de "Fora PT!" ao final da Assembleia, não trariam tantos carregamentos simbólicos como nesse contexto. E por certo, fica evidente, que o descontentamento com a gestão interna também não teve seu início nos primeiros meses de 2018. O evento aqui descrito está tão claramente imbricado com os acontecimentos externos que o "PT" aparece como um símbolo de descontentamento, de corrupção, de decepção, daquilo que se quer combater, o vilão que estava posto em escala nacional, reverberando internamente nos clamores dessa vizinhança, dessa "microcidade do interior" (PINHEIRO-MACHADO e FREIXO, 2019).

Assim sendo, gostaríamos de chamar a atenção para a forma como estes acontecimentos são vividos intensamente, com tamanha emoção que resultam da conversão recíproca dos indivíduos e do coletivo: atores e situações não inteiramente predeterminadas se revelam a eles próprios e aos outros, modificando perceptivelmente o equilíbrio de poder e a configuração de possibilidades. Esses acontecimentos devem ser entendidos como uma ação que move seus protagonistas de uma situação, de um contexto, de uma temporalidade e não vistos como algo em separado, pontual, mas em processo, parte dele, ou melhor, constitutivos de um.

Vimos aqui a política se fazendo, de fora para dentro dos muros, reverberando no cotidiano dos indivíduos, mostrando como a investigação antropológica é essencial nos contextos urbanos, para pensar a dinâmica da sociedade, que segue se modificando na forma como se organiza espacialmente e construindo novas formas de sociabilidade a serem investigadas.

${ }^{14}$ Bolsonarismo, segundo Pinheiro-Machado e Freixo (2019), é um fenômeno político que transcende a figura do atual presidente, caracterizado por uma visão de mundo ultraconservadora, que prega o retorno aos "valores tradicionais", assume uma retórica nacionalista e patriota, contrária a tudo que pode ser identificado como progressista e à esquerda. Ver também Cesarino (2019). 
Recebido em 3 de outubro de 2020.

Aceito em 27 de novembro de 2020.

\section{Referências}

BOIVIN, M. F.; ROSATO, A.; BALBI, F. A. Quando o inimigo te abraça com entusiasmo...: etnografia de uma traição. Mana, 4 (2): 35-65, 1998.

BOYD, Danah M., e Nicole B. ELLISON. Social Network Sites: Definition, History, and Scholarship. Journal of Computer - Mediated Communication, 13 (1): 210-230, 2007.

CALDEIRA, T. Enclaves fortificados: a nova segregação urbana. Novos Estudos CEBRAP, 47: 155-176, 1997.

CALDEIRA, Teresa. Cidade de Muros. Crime, segregação e cidadania em São Paulo. São Paulo: EdUSP, 2000.

CESARINO, L. Identidade e representação no bolsonarismo. Revista de Antropologia, 62 (3): 530-557, 2019.

CIOCCARI, D. (2015). Operação Lava Jato: escândalo, agendamento e enquadramento. Revista Alterjor, 12 (2): 58-78, 2015.

COMERFORD, John Cunha. Como uma família: sociabilidade, territórios de parentesco e sindicalismo rural. Rio de Janeiro: Relume-Dumará: Núcleo de Antropologia da Política/UFRJ, 2003.

COMERFORD, John Cunha. Vigiar e narrar: sobre formas de observação, narração e julgamento de movimentações. Revista De Antropologia, 57(2), p. 107-142, 2014.

ELIAS, Norbert. e SCOTSON, John. Os estabelecidos e os outsiders. Rio de Janeiro: Zahar, 2000 [1965].

FONSECA, Claudia. Família, fofoca e honra. Etnografia de relações de gênero e violência em grupos populares. Porto Alegre, Editora da UFRGS, 2004.

HEREDIA, Beatriz. "Lutas entre iguais: as disputas no interior da facção política". In: PALMEIRA, M.; HEREDIA, B. Política ambígua. Rio de Janeiro: RelumeDumará, 2010. pp.81-94.

LAGÜÉNS, J. V. M. \#Lulalivre: emoções, ritmo e estratégia em movimento. Anais da $31^{\circ}$ Reunião Brasileira de Antropologia, Brasília, 2018.

MALINOWSKI, Bronislaw. Argonautas do pacífico ocidental. São Paulo: Ubu, 2018 [1922].

MILLER, Daniel. How the world changed social media. London: UCL Press, 2016. 
MOURA, Cristina Patriota. "Vivendo entre muros: o sonho da aldeia". In: VELHO \& KUSCHNIR (Orgs). Pesquisas Urbanas. Desafios do trabalho antropológico. Rio de Janeiro: Zahar, 2003. pp. 43-54.

PALMEIRA, M. "Política, facção e voto". In: PALMEIRA, M.; HEREDIA, B. Política ambígua. Rio de Janeiro: Relume-Dumará, 2010. pp. 15-26.

PALMEIRA, M.; HEREDIA, B. "Os comícios e a política de facções". In: PALMEIRA, M.; HEREDIA, B. Política ambígua. Rio de Janeiro: Relume-Dumará, 2010. pp.27-79.

PINHEIRO-MACHADO, Rosana; FREIXO, Adriano de (orgs.) Brasil em transe: Bolsonarismo, nova direita e desdemocratização. Rio de Janeiro: Oficina Raquel, 2019.

VELHO, Gilberto. A utopia urbana: Um estudo de antropologia social. 5. ed. Rio de Janeiro: Zahar, 1989.

WYNNE, D. Leisure, Lifestyle and the New Middle Class. London: Routledge, 1998. 